\title{
Malcolm Campbell-Verduyn
}

Rijksuniversiteit Groningen, Netherlands

\section{Moritz Hütten}

Darmstadt Business School, Germany

\begin{abstract}
How do applications of emergent technologies contribute to the social legitimacy of finance? To address this question, we examine a set of technologies that have received increasing industry, media, and scholarly attention over the past decade: blockchains. Harnessing the concepts of 'moral economy' and 'scandal', we identify both possibilities and limits for blockchain applications to legitimate a range of monetary and investment activities. However, we also find that a persistent individualisation of responsibility for failures and shortcomings with 'live' blockchain experimentation has undermined the potentially legitimating aspects of this technology. Combining a reliance on technological fixes with a persistent individualist moral economy, we conclude, works against efforts to confront head-on the tensions underpinning the on-going legitimacy crises facing finance.
\end{abstract}

\section{Keywords}

Blockchain, cryptocurrency, digital money, technology, legitimacy, scandal

\section{Introduction}

The flurry of books published in the decade following the crash of 2008 serve as important reminders that the social legitimacy of finance, along with that of its key actors and processes, remains persistently fragile (Weber, 2018; Tucker, 2018; Tooze, 2018). Varying forms of 'techno-activism' have since unfolded, receiving growing scrutiny from scholars and the financial media alike for promising to rehabilitate the sector and realign its workings with the

\section{Corresponding author:}

Malcolm Campbell-Verduyn, University of Groningen, Oude Kijk in 't Jatstraat 269712 EK Groningen, The Netherlands. Email: m.a.campbell-verduyn@rug.nl. https://doi.org/10.2218/finsoc.v5i2.4137 
wider social good (Bernards and Campbell-Verduyn, 2019; Clarke and Tooker, 2018; Tett, 2019). Relying on technology in this way is far from new. Technologies have been continuously central to efforts to socially legitimate finance as a technically sophisticated realm in which uncertainty is carefully calculated, measured, and acted upon (de Goede, 2001; Omarova, 2019). Yet novel applications of expert knowledge remain double-edge swords. Whilst new technologies might enable financial activities to be understood as contributing toward wider social goals, they might also contribute to recurring problems, thereby further de-legitimating the sector. For instance, the digital modeling enabled by 'cashflow analytics' systems like Intex, which were essential to the global spreading of risk through securitised products, also contributed to the historic volatility of the 2008 global financial crisis (MacKenzie, 2010). Against this backdrop, the fintech boom of the last ten or so appears not simply as a technical story but also a moral one, raising questions about the links between technological innovation and the social legitimacy of the financial sector. Did new fintech applications contribute to the re-legitimation of finance in the wake of the 2008 crisis?

In order to address this question, the present article traces the evolution of one particularly prominent set of technologies: blockchains. Although blockchains combine a number of pre-existing technologies, including cryptography and digital time-stamping, their novelty lies in enabling secure digital transactions, and recording and publishing in quasianonymous networks. A blockchain is most simply a digital ledger bundling transactions together in 'blocks' that, when linked together, sequentially form what are meant to be immutable 'chains'. No one user can alter the record of transactions distributed across the wider network of geographically dispersed users. Applications of this seemingly esoteric peerto-peer digital technology can appear far removed from legitimacy concerns in finance, an industry sprawling across nearly all aspects of contemporary life. The ability to verify, record and broadcast digital transactions has however continually been positioned by both supporters and detractors of the technology as offering important pathways for re-legitimating finance in the wake of the 2008 crisis. The initial and still most prominent manifestation of these technologies, Bitcoin, was explicitly deemed by developers and promoters to herald a less volatile, less fraudulent and less speculative financial order. ${ }^{1}$ While cryptocurrencies now numbering in the thousands have thus far failed to fulfil such expectations, the appeal of their underlying technology has not only endured but also catalysed a wide array of blockchain applications that continue to raise hopes for re-legitimating finance.

In this article, we argue that that both Bitcoin and subsequent 'bottom-up' efforts, undertaken at the 'fringes' of mainstream financial sector, have undermined rather than contributed to the legitimacy of finance over the past decade. Our stress on technologycentred 'fringe finance' (Aitken, 2015) activities is distinguished from 'top-down' experiments undertaken within and between large banks, insurers, stock market operators and other longstanding industry actors harnessing what are increasingly referred to as 'distributed ledger technologies' (DLT). That the use of this type of more centralised 'permissioned' or 'private' blockchains has grown across the wider financial sector is indicative of the extent to which this set of technologies has become socially accepted within the financial sector. However, our interest here concerns less the legitimacy of the technology itself than its contributions to the wider social legitimacy of finance. We therefore limit our focus to the more decentralised, bottom-up applications of blockchains undertaken since the mysterious appearance of the Nakamoto white paper, which outlined design plans for its initial application to Bitcoin in 2008 (Nakamoto, 2008). These projects are best characterised as 'live experiments' being tested in real-time, unlike the more carefully planned 'top-down' blockchain experiments being tested within and between large technology and financial services, as well as central banks. 
This distinction between different types of fintech projects is important to our argument about how these 'bottom-up' experiments have been systematically individualised in ways that have sidelined efforts to promote alternative and more communal social objectives. Our analysis reveals that the potential of blockchain technologies to legitimate finance is, at once, greater than many accounts critical of this technology have suggested, as well as consistently diminished by accounts of their failures, which often stress individual responsibility for technical glitches and the 'growing pains' inevitably afflicting emerging applications (Rotolo, Hicks and Martin, 2015). Blockchains, we contend, are illustrative of the wider limits to legitmating finance through technological fixes and other forms of techno-activism.

We elaborate these arguments across three sections that draw on white papers and other primary documents outlining the intentions and goals of various blockchain applications, along with secondary reporting on their developments from a range of English-language financial and technology media. Section one introduces a pair of concepts for analysing technologycentred efforts to legitimate finance: moral economy, or the context-specific understandings of how individuals should treat and behave towards one another in socio-economic interactions; and scandal, or the process through which transgressions of dominant moral standards are exposed outside the confines of a narrow community. By individualising failures associated with activities that challenge dominant standards of behaviour, we argue that scandals perpetuate rather than shift the moral economy of finance in ways that ensure the persistence of the industry's fragile legitimacy.

Section two then uses the concepts of 'moral economy' and 'scandal' to trace the varying values underpinning blockchain technologies that have been exposed since 2008. We show how blockchains afford novel possibilities for communal and more socially productive activities than more deterministic understandings of their applications provide for. Early blockchain developers sought to collectivise responsibility and inject alternative moral principles into finance in novel ways. Yet media and scholarly attention de-emphasised the collective intentions of these projects while individualising the failings that inevitably arose with these 'live experiments'. We trace the framing of Bitcoin and related experiments beyond narrow developer communities in manners that continually emphasise individual failure and background collectivist intentions. This analysis highlights the varied agency exercised by media, governments, and other observers in scandalising emergent applications of the technology in ways that persistently undermine their potential contributions to the legitimacy of finance.

Finally, section three examines the potential for recent blockchain experiments to contribute to the wider legitimation of finance. Without more fundamentally addressing the paradox of using individualistic technologies to pursue collectivist goals, we conclude, blockchain experiments in finance will continue being scandalised as public attention beyond narrow developer communities grows. Stressing the limits of technological fixes to resolving the legitimacy crisis facing finance, we concur with recent contributions to this journal that find that blockchain applications ultimately "fail to challenge a received logic of finance" (Lotti, 2016: 96).

\section{Moral economy, responsibility and legitimacy in scandalous times}

Legitimation involves a set of processes through which narrow sets of socio-economic practices come to be seen as contributing to the good of a wider community. The work of positioning financial practices within broader social goals can be traced, understood and 
measured in several ways (Baker, 2018; Rethel, 2011). Here we harness moral economy, a concept pioneered by English historian E.P Thompson (1971) in his study of legitimation within the context of the eighteenth-century labour movement.

The concept of moral economy presupposes that the economic activities of production and consumption, as well as those of exchange and investment, are always normatively grounded in specific understandings of how agents treat and behave toward one another. Understandings are pluralised here since, as Thompson lucidly argued, multiple moralities coexist at any given time or place. Yet from a range of available moralities, a certain set always tends to dominate, coming to be regarded as 'natural', merely 'the way things are' and how they should always be. The moral economy concept explains this as the product of a specific and ultimately contestable "inter-subjective consensus concerning appropriate economic goals, principles, values and activities” (Baker, 2018: 294). Foregrounding 'moral economies' therefore highlights the hegemony of a particular set of moralities at any one point in time, while also underlining the crucial role of human agents in working to shift normalised assumptions about how things should be.

In terms of post-2008 global finance, the concept of moral economy directs our attention to how the values underpinning methods of exchange, credit allocation and investment remain entangled in an "on-going interactive process, in which normative claims and their systemic vision are advanced, accepted, rejected or modified" (Baker, 2018: 296). Recent studies have noted a tendency to attribute blame to individual financiers, like the CEO of Lehman Brothers, Dick Fuld, or even individual countries, like Greece (Fourcade et al., 2013; Aldohin, 2016). Individualising responsibility for financial failure in this way can sometimes risk overstating the significance of specific instances of wrongdoing and fraud (Czarniawska, 2012). On the other hand, the post-crisis fining of large banks has been shown to levy responsibility for wrongdoing collectively on shareholders and some non-executive staff, rather than the individual executives that oversaw the fraudulent behaviour in question (Campbell-Verduyn, 2017a; de Goede, 2015). A moral economy framework helps navigate this complexity by problematising commonly held notions that morality necessarily refers to socio-economic practices supportive of a broader common good (or what we term here the collectivist position).

Luckmann (2002) has criticised the tendency of social theory to dichotomise selfish, short-term and individualistic behaviour, on the one hand, and more communal activities focused on longer-term goals, on the other. This split is perhaps most clearly reflected in the division between 'classical' approaches to microeconomics, said to be grounded in individualist moralities, and 'Keynesian' macroeconomic approaches, which instead foreground a more "socially-attuned ethical vision" (Best and Widmaier, 2005: 622). Working with 'moral economies' provides for a more nuanced understanding of such dichotomies, drawing attention to continuities as well as changes in dominant standards regarding how people should act towards one another in particular times and places. As Whyte and Wiegratz (2016: 5) have argued, this means avoiding the temptation to view moral economy as "automatically refer[ing] to pro-social practice" (see also Palomerra and Veta, 2017). Despite its popular mantras of 'greed is good' and 'I'll be gone/you'll be gone' (I.B.G/Y.B.G), finance need not be understood as entirely dominated by individualistic and self-serving interest.

Moral economy therefore provides a more nuanced understanding of the moral shifts and continuities in actually existing political economies. On the one hand, it spotlights a growing concern for collective responsibility in post-2008 finance. Discussion amongst financial professionals since the crisis has widely emphasised issues relating to equality, stability, justice and fairness beyond simple profit making (Campbell-Verduyn, 2017b). Efforts to advance the Socially Responsible Investment (SRI) agenda through more specific metrics of 
Environmental Social Governance (ESG) have gained renewed traction in further attempts to re-position finance as more than a mere realm of individualised accumulation. These and other 'pro-social' initiatives emphasising seemingly more collectivist 'macro'-moralities have of course been spurred in part by high-profile grassroots activist movements, like Occupy Wall Street, which challenged the financial sector on the grounds that it fuelled growing socioeconomic inequality. Rather than being indicative of any wholesale shift towards a more collectivist financial sector, post-2008 financial activities have become more reflective of the persistent struggle and contestation over moral values across the sector.

A second and related benefit of harnessing the moral economy concept is that while change is possible, dominant standards of how to act and behave towards one another are difficult to fully uproot. Change in a prevailing moral economy often entails more of a blending or mixing of competing visions of how to treat or act towards one another. Moral economies rarely swing from 'purely' hyper-individualistic to 'purely' hyper-collectivist (or vice versa). While some extreme events, such as revolutions, may instigate profound changes in dominant moralities, events like crises can produce mere incremental change to dominant moralities. Despite its historic nature, the crisis of 2008 is now seen as a 'status quo crisis' (Helleiner, 2014), particularly in the global governance of finance (Moschella and Tsingou, 2013).

Nuanced patterns of continuity and change in the moral economy of global finance can be further unpacked using the concept of scandal. Episodes of scandal reveal moral transgressions beyond narrow communities, granting unique insight into the on-going quarrels among competing moralities underpinning financial practices precisely because they involve explicit articulations of normative expectations and incoherencies (Adut, 2008). As processes, scandals involve activists, journalists, whistle blowers and other actors exercising agency by more widely publicising internal transgressions of dominant standards of behaviour. As instruments, scandals advance certain material interests (such as those of agents able to sell advertising), as well as particular ideologies that can either challenge or reinforce existing social norms. Scandals, however, typically provoke responses that reinforce the status quo and "assure us of the wider morality of a particular practice or social order" (Johnson, 2017: 704). Scandals can thereby reinforce the kind of hyper-individualism long dominant in finance through their tendency to "individualise and isolate transgression" (Johnson, 2017: 704). Individualising blame is pervasive in scandals where responsibility is asserted through "strong plots' and archetypical stories geared towards identifying villains responsible for wrongdoing (Czarniawska, 2011). Scandals tend to shift attention away from questions of collective or systemic responsibility and change, while simultaneously focusing attention onto individual failings and blame. The ability to enact "shame, humiliation, outrage, [or] disgrace" is itself enhanced when specific individual persons or institutions, rather than more general, collective, or wider structural issues and practices, are identified as worthy of blame (Dagnes, 2013: 1). Gendered studies of finance have, for example, have highlighted how emphasis on individual wrongdoings, such as those revealed in sex scandals like that involving the former IMF Managing Director, Dominique Strauss-Kahn, produced a rapid post-crisis return to 'normalcy' in which deeper, structural problems failed to be addressed. Instead, individual 'wonder women' were upon called to serve as 'silver bullets' in rectifying the wrongdoing of men, like Strauss-Kahn, who long dominated the upper echelons of the global financial system (Hozić and True, 2016).

The persistence of dominant pre-crisis norms of conduct in the financial sector is therefore entrenched by scandals individualising responsibility for wrongdoings in the wake of the 2008 crisis. The public revelations of the British payment protection insurance 'misselling scandal', the American 'foreclosure scandal' and the various 'market manipulation scandals', 
including the rigging of key interest rates and foreign exchange markets, all assigned responsibility to individual action by particular banks or individuals within banks (e.g. Bavoso, 2016; Ellis, 2016). Responsibility for these events turned "systemic problems into issues of individual failing" (Hozić and True, 2016: 11). As an instrument for positive change, scandals remain rather ambivalent for journalists, activists and others caught between the tasks of advancing a narrative that resonates with wider audiences and the very real risk of shifting attention away from systemic issues. For others, however, such ambivalence is most welcome, for example when scandalising migration diverts blame for economic downturn away from structural problems. Scandals, in short, illustrate how revelations about normative transgressions work to entrench individualistic moral economies while underplaying wider structural problems.

These patterns of continuity and change in moral economies, exposed through events like scandals, thereby provide useful opportunities for tracing how certain socio-economic practices are perceived as contributing to broader collectivist goals. In the following section, we evaluate how a set of technology-enabled responses to the global financial crisis have produced a mix of moral continuity and change, which combined, has failed to enhance the legitimacy of finance in the post-crisis period.

\section{Blockchain technologies as stumbling blocks to financial legitimacy}

Debates around blockchain have frequently linked the moralities underlying this set of technologies to the acquisitive and self-serving ethos typically regarded as dominating finance. Most prominently in the academic literature, Golumbia (2016) associates their initial application to Bitcoin with the type of market libertarian ideology and American-style 'rightwing extremism' that has long been concerned with 'freeing' money from collectivist control by the state (Paul, 2009). Bitcoin has been widely promoted for enabling direct exchange among individuals in ways that are protected from the types of collective state action undertaken at various moments in history, including in response to the 2008 and later Eurozone crisis (Cox, 2013). In scholarship and public discourse alike, blockchains tend to be presented as individualistic solutions to the problems afflicting collectivist attempts to maintain a single legal tender (Ametrano, 2016; Karlstrom, 2014). Prominent economists have joined in too, characterising Bitcoin as "antisocial" (Krugman, 2013b) or an illegitimate attempt to further undermine collective goals, such as fighting "corruption and tax evasion and tax avoidance" (Joseph Stiglitz quoted in Montag, 2018). In a more nuanced vein, some have argued that blockchain technology incentivises individualist conduct through 'gamification', a process of rewarding the winners of algorithmic guesswork with new monetary tokens, resulting in a continual race amongst users to verify transactions by resolving complex equations (DuPont and Maurer, 2015).

At the same time, however, others have emphasised the connection of blockchain technology to varying forms of what we refer to as techno-collectivism. Swartz (2018) has positioned Bitcoin alongside mutualistic self-help and cooperativist visions of human society, in which 'everyone does their part' to ensure privacy and the integrity of the overall network. These goals are enabled by the open source nature of the computer protocols underlying Bitcoin and other blockchain experiments, developed in communities of programmers who maintain the underlying coding. Nigel Dodd (2018) similarly associates Bitcoin with a diverse set of social movements pursuing a shared goal of establishing universal world money, which can also be understood as a collectivist attempt to overcome the compartmentalisation of 
monetary regimes into individual nation-states or regions. Bousfield (2019) understands cryptocurrencies as 'networked social movements', while DuPont (2019) stresses how blockchains are fundamentally 'social technologies' encouraging users to experiment with novel forms of coordination. While each of these studies interpret the 'social' nature of blockchains in a different way, they helpfully complicate the notion that blockchains are merely asocial or antisocial.

Taken together, how can these competing visions of blockchain help us understand the impacts of their applications on financial legitimacy in the post-2008 period? This section traces how shortcomings and problems arising from blockchain-based efforts to reform money and investment have been continually scandalised in manners that have largely perpetuated moral continuity and contributed little to the legitimacy of post-2008 finance. Our analysis begins with Bitcoin and proceeds to trace the wider range of financial experiments with blockchain technology undertaken since 2009.

\section{Scandals surrounding blockchain-based monetary experiments}

Growing public interest in the initial cryptocurrency, Bitcoin, stressed individual responsibility for three primary features of the currency, all of which were quickly scandalised following the 2013 'Bitcoin crash'. These were its mysterious origins and ambitious objectives, its speculative nature, and its association with illicit activities. Attention in both mainstream and more specialised financial industry media centred on the specific individuals responsible for ostensibly problematic features of the technology, rather than on the wider structural problems this novel monetary experiment set out to address.

In a first instance, it is not too far of a stretch to claim that, after the 2013 crash, public concern with Bitcoin was focused on the individual(s) responsible for the 2008 Nakamoto white paper, which outlined the technical design of the first cryptocurrency. This persistent focus on the individual(s) responsible for the design of Bitcoin obfuscated wider discussion of the collectivist nature of the challenge this monetary experiment posed to Westphalian moneys. In particular, problems that the original cryptocurrency developers and advocates sought to overcome - such as the creation of money by individual private banks and central banks - were overlooked (e.g. Krugman, 2013a). Meanwhile, the longstanding features of an international monetary system stricken by recurring crises remained naturalised, seen as part of a taken-for-granted common sense. That an anonymous individual using the pseudonym, Satoshi Nakamoto, would dare to propose a universal money distributed across a shared network of users was interpreted as a threat to the status quo moral economy in which individual financial institutions alone create moneys. The socio-economic and moral justifications for Nakamoto's proposals were thus largely set aside in favour of focusing on the mysterious identity of this individual or group of individuals. Similarly, the efforts of Bitcoin developers and promoters to re-centre a universal currency around shared information (rather than individual national identities) were also largely sidelined. Little credence was given to either of these structural challenges as scandalisation focused attention above all on identifying Nakamoto (De Filippi and Loveluck, 2016: 26, fn. 11).

In a second instance of scandalisation, wider interest in Bitcoin became increasingly fixated on the individuals responsible for major swings in its US dollar exchange rate. The price of Bitcoin in the leading international exchanges peaked at $\$ 1,242$ in late 2013 , only to drop by half over the following three months. Among the numerous causes for this volatility identified by observers (e.g. Kristoufek, 2015), blame was typically assigned to a sudden break 
in the leading institution facilitating cryptocurrency-to-fiat money exchange. Bearing the brunt of media and later policy attention was Mark Marie Robert Karpelès, the French CEO of Tokyobased Mt. Gox, who was eventually charged with embezzlement by Japanese authorities. The personalisation of this event sidelined discussions of the wider structural problems associated with foreign exchange markets, which themselves have long suffered intense periods of volatility. Only infrequently was media attention devoted to the solution Bitcoin proposed for a cosmopolitan or universal form of money (Dierksmeier and Seele, 2018). Once again, the collectivist aspect of Bitcoin's challenge to state-moneys was downplayed in favour of a narrower focus on individuals actors, this time those charged with currency speculation.

A further instance of scandalisation was Bitcoin's constant association with illicit online markets and, in particular, the deep web online marketplace, Silk Road, whose first iteration exclusively accepted the original cryptocurrency. Stress on the legal and moral wrongdoings of Ross Ulbricht, the 30-year old Australian who was eventually convicted of money laundering and drug trafficking by American authorities in 2015, obfuscated the degree to which Bitcoin underpinned a market that sought to challenge established norms of digital exchange. As more nuanced anthropological studies have noted, the original version of Silk Road was a site designed for illicit activity, but also one of "social resistance by using online technology to build an alternative reality that enables peer-to-peer trading of drugs and associated discussions of drug-taking" (Maddox et al., 2016: 111-12). Silk Road was explicitly promoted as a libertarian experiment, resonating with traditional beliefs about how the Internet more generally could reconfigure relations of power and enable freer exchange. Beyond the dominant negative media framings, Silk Road, as a community, offered online space that permitted the exercise of personal freedoms through Bitcoin without the stigmatisation frequently bestowed upon drug users and consumers of illicit goods and services. More than just facilitating the buying and selling of illicit products through the initial cryptocurrency, Silk Road provided a forum for collective discussion of drugs, drug culture and wider debates about the social treatment of drug users. In interviews, market participants explicitly mentioned a sense of joining a "moral fight" fuelled by a desire for "personal freedoms", at least in the early versions of Silk Road (Maddox et al., 2016: 120). Participants interviewed following the first shutdown of Silk Road lamented the "reduction in trust in the online environment, and a sense of loss for the political vision of a different future" (Maddox et al., 2016: 123).

The broader scandalisation of Bitcoin through its association with individual legal transgressions did little to help shift the dominance of the moral economy underpinning the legitimacy of finance. In their tendency "to command the public imaginary" (Hozic and True, 2017: 271), the continual 'crypto-scandals' surrounding Bitcoin highlighted individual actions and wrongdoings over the technology's implicitly collectivist efforts to address some of the wider structural problems afflicting global finance as well as other social issues, like drug use. Widespread focus on the individuals responsible for the design, exchange rate volatility and use of Bitcoin in illicit markets provided little in the way of an acknowledgement of how blockchain technology could make a positive contribution to the fragile legitimacy of a sector characterised by speculation, fraud and other pathologies growing in both intensity and frequency since the 1970s.

\section{Scandals surrounding blockchain-based investment}

The earliest alternative to the Bitcoin blockchain, Ethereum, distinguished itself as a platform for experimenting with novel forms of investment through so-called smart contracts. These are digital contracts with pre-agreed conditions stipulated by the parties to the transaction, which 
become triggered automatically. Rather than having to wait for the decision of a neutral third party, smart contracts enable real-time decision-making. Responsibility is thereby devolved onto the parties to the contract collective rather than an individual third party, a legal authority, or a political office. This arrangement seeks to increase clarity and better share responsibility for the terms set out in the contract.

Bundled together, smart contracts have been aggregated to form so-called decentralised autonomous organisations (DAOs). These seek to do away with human management in matters like capital allocation within investment projects, for instance. Instead, decisions are made only on the pre-agreed terms, ostensibly determined in a more transparent, efficient, fair and democratic manner. By cutting out the middlemen, DAOs and their underlying smart contracts can potentially advance collective goals rather than merely individual gain. Yet, in practice, decentralised forms of investment harnessing blockchain-based technologies have been scandalised for their glitches, shortcomings and failures.

The first start-up on Ethereum to gain broad public attention was a crowd-funding project ambitiously named, The DAO. Developed by the German company, Slock.it, The DAO was meant to gather together community project proposals and hold votes on which to invest in (Jentzsch, 2016). Its developers explicitly promoted the benefits of pre-programmed code rather than active human management. By removing the potential for individual human error, The DAO would foster collective responsibility for pre-agreed upon and automatically managed investments, cutting out financial intermediaries. Although marketed as a revolutionary new form of investment that would empower investors collectively while enabling contributions to a wider range of social issues, The DAO suffered a major setback that was quickly scandalised in a manner that drew attention away from wider structural problems in existing modes of financial investment.

Prior to the end of The DAO's initial 28-day funding period, concerns arose regarding a technical flaw that might allow an attacker to withdraw funds raised through the application (Vessens, 2016). Considerable attention was focused on a founder of Slock.it, Stephan Tual (2016), who continually vouched for the impossibility of this event even as The DAO was hacked and drained of funds only days after its initial funding round was completed. The attack on The DAO attracted widespread coverage and debate. Large media organisations, such as The New York Times, chronicled the events that led to the theft of approximately $\$ 60$ million, yet focused blame on the individuals responsible for programming the code and the hackers (Popper, 2016). Meanwhile, hope was placed in the co-founder of Ethereum, the then 22-year old Russian-Canadian programmer, Vitalik Buterin, to save The DAO by changing the code of its underlying blockchain, despite the fact that such action would undermine the supposed immutability and neutrality of the technology (DuPont, 2017: 170-2). Lost in this scandal were more fundamental issues raised by the technology's stated aim of preprogramming the collective management of investment. The larger debate between individual human management and collectively automated investment was only rarely considered, and the personalisation of problems with The DAO and Ethereum as a wider project overlooked the novel, bottom-up attempts to collectivise financial investment.

Instead of collective reflection on the limitations of smart contracts and technological efforts to shift the moral economy of financial investment more broadly, the failure of The DAO prompted further experiments from individual start-ups to harness smart contracts for developing so-called Decentralised Applications (DApps) for various 'pro-social' goals. The charity DAO, for instance, sought to provide its so-called 'investor-donors' collective control over causes they wished to fund by committing investment based on pre-agreed 'milestones of progress' (Redman, 2016). Similarly ambitious projects, such as Giveth, Benefactory.cc, and 
Alice.si, have arisen to develop pre-programmed digital charity platforms. While transparent about their transaction histories and invoking lofty collectivist goals, these projects have remained continually susceptible to the individualisation of problems inevitably arising from such live technological experimentation. Given the powerful roles of programmers with specialised skills, these projects remain open to scandals in which failures are attributed to a hierarchy of elite insiders. Such limits are most vividly apparent in the explosion of what became known as Initial Coin Offerings (ICOs), of which The DAO was arguably the first to raise funds in this novel manner.

Rather than providing ownership shares as in initial public offerings (IPOs), ICOs raise funds by distributing digital tokens. These do not represent any ownership and decisionmaking stake. Instead, they are simply tokens that may one day become valuable should the specific project they represent actually materialise. After The DAO, a wave of projects promised to herald more socially responsible financial investment goals. Start-ups promoted ICOs as a way of raising much-needed funds and many claimed to be 'democratising' investment by giving small investors access to opportunities previously reserved for the likes of venture capitalists and other professional investors (OECD, 2019). Meanwhile, growing inequality and the widening gap between wealth creation and distribution in many countries further enhanced the democratising allure of these technological experiments. Specific ICOs, such as eHarvestHub, promised to empower marginalised groups and enable 'fairer' economic exchange, while others pledged to enact shared collectivist principles and empower marginalised ethnic, gendered and religious groups. For instance, the HADA Dbank sought to raise funds through DAOs in order to become the "1st Digital Bank to fuse Islamic Banking Module with Blockchain Technology”. 2 Self-declared 'virtuous' organisations, like The Women's Coin Foundation, held ICOs, as did others seeking to enact responsibility for the shared fate of the natural environment, such as the SolarDAO and the DAO Integral Platform for Climate Initiatives.

Despite their collectivist promises, many of these ICOs became scandalised as the wider popularity of blockchain-based investment boomed after 2017. Individual examples of blockchain-based start-ups raising sums equivalent to millions of US dollars and promising returns for early investors of up to $950,000 \%$ attracted mocking headlines. ${ }^{3}$ ICOs selling tokens under plainly absurd terms grabbed media limelight. Attention was particularly focused on the token purchase agreement of EOS, one of the top five highest-valued blockchain-based projects representing a (hypothetical) market capitalisation of over $\$ 9$ billion, whose token purchase agreement exclaimed in capitalised letters that "EOS TOKENS HAVE NO RIGHTS, USES OR ATTRIBUTES". ${ }^{4}$ Investors appeared to treat such disclaimers as a necessary concession to existing legal frameworks while nevertheless expecting and trusting developers to eventually make good on their lofty promises. Responsibility for what blockchain skeptic Nouriel Roubini (2018) dubbed 'Initial Coin Scams' continually rested with investors and promoters. Individualisation of responsibility focused on celebrities who had backed prominent ICOs, such as boxer Floyd Mayweather's endorsement of an ICO whose founders were later charged by the American Securities and Exchange Commission with fraud after raising \$32 million in 2018. Public attention on these and other individual actors, however, underplayed the wider structural problems in global finance that ICOs initially sought to address. Individualised blame during and after the ICO craze of 2017-18 focused largely on greed, fraud, and irresponsible investors.

Scandals like these underplay the link between novel forms of financing and communitybased open source approaches to programming software. Instead, ICOs and other projects harnessing blockhain technology for investment are continually relayed to investors as 
exposing them to 'fear, uncertainty and doubt' (sometimes called FUD, or 'FUDing'). Rather than legitimating finance in the aftermath of the 2008 crisis, the persistent individualisation of responsibility for the problems with many ICOs, like those of blockchain-based monetary experiments, undermined the stress of their more collectivist goals to democratise investment. Will this always be so? Can bottom-up blockchain financial experiments being undertaken 'live' ever hope to overcome this tendency toward scandalisation?

\section{Blockchain and the limits to techno-financial solutionism}

Financial applications of blockchain technology may have the potential to promote collectivist outcomes, but so far this potential has yet to materialise. In this section, we contend that cryptocurrency alternatives to Bitcoin and other monetary experiments promoting lofty "prosocial' goals are unlikely to avoid scandalisation should they gain wider traction because of the way 'live trials' with emergent technologies tend to interact with the moral economy of scandal. In particular, we argue that the persistent reliance of blockchain experiments themselves on a high degree of individualism means glitches and setbacks in the experimentation process are predisposed to scandalisation, thereby undermining their potential to shift rather than perpetuate the existing moral economy of finance.

\section{The mixed moral economy of altcoins}

Like Bitcoin and the novel experiments with blockchain-based investment detailed above, the broader population of 'altcoins' developed in the post-2008 period are frequently underpinned by more mixed moralities than is typically assumed in general critiques of the cryptocurrency movement. As some more nuanced studies have noted, altcoins can "radiate positive and optimistic ethical and political promises" (Coeckelbergh and Reijers, 2015: 177). Indeed, some alternatives to Bitcoin seek to overcome the structural problems plaguing both contemporary finance and those afflicting the original cryptocurrency. These kinds of monetary experiments have tended to advance three broad collective goals, each of which holds a potential of enhancing the legitimacy of finance.

First, there are those altcoins that seek to remedy the pathologies of Bitcoin. So-called 'privacy coins', for instance, like Monero, Zcash and Zerocoin, were developed to provide more complete forms of anonymity in digital transactions, overcome the quasi-anonymity of Bitcoin, and bypass the increasingly sophisticated state and corporate surveillance structures of online commerce. Meanwhile, 'stablecoin' projects like SagaCoin, Tether, USDCoin and others have sought to address the exchange rate volatility of Bitcoin. These altcoins are pegged either to the dollar or to a wider basket of currencies. In their efforts to provide correctives to the problems that have plagued the initial and still most prominent cryptocurrency, these alternatives seek to strengthen Bitcoin's attempt to establish a common 'world money' that overcomes the volatility and privacy issues associated with state-backed currencies.

A second group of altcoins distinguish themselves from Bitcoin in explicitly seeking solutions to a wide variety of socio-economic ills. Dash, for instance, positions itself as an answer to hyperinflation in countries like Venezuela, where the use of this Bitcoin competitor has expanded (Zastrow, 2018). Developers of this and other explicitly 'pro-social' altcoins promote democratic ways of fostering collective responsibility through digital assemblies that come together in online chat groups with low-barrier digital tools. Faircoin developers, for instance, continually emphasise the importance of building collective regional networks in developing their altcoin. Although abandoned by its original creator (O'Leary, 2018), anti- 
capitalist activists bought nearly all-existing Faircoins during 2014 and repurposed the cryptocurrency in line with their more collectivist moral convictions. Their adaptations ranged from implementing a transaction verification add-on through a novel 'proof-of-cooperation' to using open source software, like Fairchat, to foster environments more inclusive of non-English native speakers. The overall emphasis of Faircoin and other cryptocurrency experiments of this kind tends to be on enabling wider 'community' participation, as well as empowering marginalised groups, all the while enabling 'fairer' socio-economic exchange. Even Dogecoin, a cryptocurrency famous for being based on an Internet meme, notably had a "long-term monetary policy aimed at inclusivity" (Jeong, 2018: 64).

A third category of "pro-social' cryptocurrencies also wants to enact shared collectivist principles, specifically focusing on empowering various ethnic, gendered and religious groups or minorities. This commitment is typically reflected in the very name of the altcoin. For instance, ScotCoin, CROAT and The Sovereign were all developed or harnessed in support of sub-national independence movements in Scotland, Catalonia and the Marshall Islands, respectively. PROUD money has sought to empower the international LGBTQ+ community, while ChristCoin and Bitcoen are meant to enhance solidarity between the globally dispersed Christian and Jewish communities, respectively. These currencies explicitly aim to embed monetary-like transaction systems within online communities in ways that foster and promote collectively shared values. Further, 'pro-social' monetary experiments with blockchain applications also seek to more widely enact responsibility for the shared fate of the planet. VeganNation tries to promote sustainable food consumption, SolarCoin incentivises the production of solar energy, while EverGreenCoin and TreeCoin plan to plant trees to offset the extensive energy consumption associated with verifying and maintaining cryptocurrency transactions (on this see de Vries, 2018). Although endorsing a range of varying social causes and appealing to different communities, collectively these experiments reflect fundamentally technology-centred attempts to group together geographically dispersed individuals in support of shared moral causes.

\section{The tendency toward scandal in fintech experimentation}

Despite their noble aims, competing altcoin projects remain highly vulnerable to being scandalised should they gain wider traction beyond narrow developer communities. A key limitation of these projects is that they tend to rely on applying individual incentives for steering user conduct towards specific ends, like casting votes, providing renewable resources, or engaging with content linked to a particular social cause. In stark contrast to their frequent references to collective goals, the actualisation of shared responsibility for the planet, for specific social causes, or for society as a whole relies on a type of "unity without solidarity" (Molnar, 2005, in Arthur, 2012: 104). As a result, these technological experiments can mistake fickle investors for activists in support of a social cause.

Granted, collectivist social responsibility is inherently difficult to actualise in projects that are fundamentally based on binary computer code. Yet, explicitly invoking notions of collective responsibility without building alternative values into the actual operation of their cryptocurrencies limits these projects in terms of their ability to challenge to existing moral economies. Pro-social altcoins thereby tend to function as forms of click-activism, which seek to enhance participation and novel forms of input by claiming to represent populations supporting causes grouped by faith, sexual orientation, gender, and so on, while often achieving very little in the way of distributing material benefits to these stakeholders. Large gaps become apparent between their lofty goals of fostering shared responsibility and the 
actual technical work required in order to realise these outcomes. Continuous reliance on individualism for actualising collective goals means that such projects remain at risk of becoming scandalised as their development suffers inevitable setbacks.

Alternatives to Bitcoin illustrate how cautiously positive examples of blockchain activism both thrive on, and are ultimately limited by, technological solutionism. They reveal how collectivist moralities are difficult to operationalise through technology alone, particularly with technologies that have largely untested and unpredictable applications. Most pro-social cryptocurrency projects present no clear path in terms of how alternatives to individualistic moralities should actually be implemented or maintained in practice. Instead, they typically overextend domain-specific concepts, like consensus or immutability, in order to fuel the impression that blockchain technologies will somehow, on their own, enforce and maintain collective goals. We can identify at least three specific issues constraining the realisation of pro-social cryptocurrency goals, which also risk further scandalisation should these projects begin receiving wider attention.

First, altcoins often assume that moral diversity will magically materialise in technological projects involving a mere payment token with no discernible special properties other than a suggestive name given to it by developers. Second, this particular type of technological experimentation tends to rely on unquestioned assumptions about consumer citizens, ethical consumption and voting with one's pocketbook (or digital wallet). Aside from their proclaimed goals, altcoin projects centre around the idea that blockchain technology - on its own enables the very creation of funds needed to partake in more ethical consumption and other forms of collective action. Third, and relatedly, pro-social cryptocurrency projects tend to promote themselves on the grounds of being based in a technology that, in and of itself, does little to overcome the problems of mobilisation and community building they claim to address.

Considering these limits, we see alternative cryptocurrencies and other financial applications of blockchain technology as unlikely to transform or re-legitimate finance in any novel manner. Despite invoking lofty collective principles, these projects persistently rely on individualistic logics of engagement in ways that not only seem unlikely to actualise moral change, but also seem far more likely to attract speculative investment from individuals seeking short-term profit. Like the dotcom boom of the late 1990s, the various investment bubbles in cryptocurrency markets - such as the 2017 boom, which involved exponential stock price increases for companies which did little more than include the word 'blockchain' or 'Bitcoin' in their names - reveal just how susceptible the sector is to 'new era' mania. ${ }^{5}$ The inevitable fizzling out of this boom will only enhance distrust and skepticism about blockchain experiments in finance and beyond, making it even less likely that the underlying technologies will transform the prevailing moral economy of finance.

\section{Conclusion}

Despite promising to inject a sense of collective responsibility into the operations of finance, bottom-up applications of blockchain technology have not and are not likely to contribute in any meaningful way to a transformation in the social legitimacy of finance. While blockchainbased projects advance much more complex moralities than critics typically acknowledge, their reliance on emergent technology and 'live experimentation' for accomplishing mutualist or collectivist goals opens them up to being scandalised in ways that support the status quo. By focusing attention onto individual transgressions of existing behaviour standards, scandals obscure the collectivist intentions of projects with the potential to shift the dominant moral forms of the financial economy. The focus on individual wrongdoing obfuscates both the pro- 
social orientation of many blockchain projects, and blocks further attempts to overcome the systemic problems contained in early applications of blockchains, such as Bitcoin and the failure of The DAO. Accordingly, such scandals perpetuate rather than catalyse change in the moral economy of finance.

Short of any more profound engagement with the paradoxes of relying on individualism and technology for promoting collective goals, we concur with other analyses of social movements in finance which conclude that blockchain-based initiatives will "unwittingly help to sustain the existing organisation and operation of financial markets" (Scholte, 2013: 145). When largely untested blockchain monetary and investment projects encounter the glitches that accompany 'live' experimentation, the individualisation of responsibility for their inevitable hiccups and failures is likely to distract from any collective challenge to the existing moral economy of finance. The Achilles' heel of blockchain-based finance appears to be a rather deep reluctance on the part of developers, investors and other participants in 'bottom-up' experiments to become involved in the more detailed planning necessary to actualise their "pro-social' goals. Beyond the "heavy intellectual lifting" (Baker, 2018: 305) required to outline and promote distinct moral visions, the practical details of the mundane tools required for actualising moral change require continual interrogation, re-framing and concrete action beyond slogans and mere tokenism. Instead of overselling the revolutionary potential of any one application or technology, more profound exploration and efforts are required in order to resolve the tensions entailed in using new technologies to pursue collective goals, shift moral economies or transform finance.

Finally, the continual scandalisation of bottom-up blockchain activities may actually put the 'top-down' experiments of large banks and other financial industry actors in the driving seat when it comes to pioneering new forms of collectivism. Consortia, banks, insurers, stock market operators and technology firms have also been involved in developing communal applications of so-called 'private' and 'permissioned' blockchains, primarily geared toward enhancing the efficiency of their back office processes, but with as yet unclear implications for the broader sector. Further studies might productively assess whether or not these experiments work to enhance the wider legitimacy of the financial industry. A particularly important trait of these 'top-down' experiments is their far longer gestation period. Swartz (2018) considers these more careful and slowly moving types of blockchain projects as developing an 'infrastructure of mutualism', yet it may be that such novel forms of industry mutualism only pave the way for yet more of the longstanding competitive individualism that characterises finance. Indeed, consortia such as R3 have witnessed precisely this type of individualistic disagreement between founding partners, with Goldman Sachs, Morgan Stanley and Santander dropping out of the project citing fundamentally "diverging interests" (Stafford and Murphy, 2016). There is furthermore increasing competition between DLT consortia, which are themselves divided by geography, with the 'Western' Enterprise Ethereum Alliance positioned, for instance, against Chinese consortia like ChinaLedger and Financial Blockchain Shenzhen Consortium. Rivalry and internal disagreement may even prompt top-down blockchain-based initiatives to be scandalised, if and when they gain wider public prominence beyond the communities immediately involved.

More broadly, we believe that the concepts of 'moral economy' and 'scandal' will remain useful for research tracing the contributions of these and wider technology-centred efforts to legitimate finance and other sectors of an increasingly financialised global economy. Contemporary and historical instances of scandalisation will be particularly interesting to explore in view of developing a better understanding of the evolving efforts of too-big-to-fail financial institutions, as well as smaller fintech start-ups, to socially legitimate their activities 
(Hendrikse et al., 2018). Furthermore, 'moral economy' and 'scandal' can enable reflexive consideration of the role that scholarly critiques themselves may play in steering attention towards individualised failures rather than collective efforts to more profoundly challenge existing standards of behaviour. This is particularly prevalent in the type of technical, legalistic and economistic analysis thus far dominating both scholarly literature and media coverage of blockchain and fintech. ${ }^{6}$ Finally, much can be gained from further tracing how individualisation is potentially programmed into algorithms that increasingly assemble and disseminate the events unfolding in narrow communities to wider audiences. The particular moral economies portrayed in novels, films, comics, and theatre representations of financial activities can also serve as useful objects of analysis for investigating shifting moral economies going forward.

\section{Acknowledgments}

We are grateful for feedback received from the two journal reviewers and editors, as well as participants in the the 2018 Finance and Society Network Conference in Edinburgh and the 2018 European Workshop in International Studies on 'Wrongdoing, International Scandal, and the Politics of Responsibility'. Moritz Hütten has also benefited from funding by the HansBöckler-Stiftung, project number 2017-437-2.

\section{Notes}

1. Unless otherwise noted, references to Bitcoin are to Bitcoin Core rather than Bitcoin Cash.

2. https://www.hada-dbank.com/

3. More conventional tech start-ups struggle to accumulate anywhere near a million USD in seed investment. For the relevant data on ICOs, see <https://icostats.com/roi-since-ico/>.

4. https://eos.io/purchase-agreement

5. Long Island Iced Tea Ltd., for example, saw its stock price increase by nearly $200 \%$ after changing its name to Long Blockchain in late 2017. See Detrixhe (2018).

6. For an overview of blockchain literatures, see <https://www.blockchainresearchnetwork.org/ $>$.

\section{References}

Adut, A. (2008) On Scandal: Moral Disturbances in Society, Politics, and Art. New York: Cambridge University Press.

Aitken, R. (2015) Fringe Finance: Crossing and Contesting the Borders of Global Capital. New York: Routledge.

Arthur, C. (2012) Financial Literacy Education: Neoliberalism, the Consumer and the Citizen. Rotterdam: Sense Publishers.

Baker, A. (2018) Macroprudential regimes and the politics of social purpose. Review of International Political Economy, 25(3): 293-316.

Bavoso, V. (2016) Financial innovation, derivatives and the UK and US interest rate swap scandals: Drawing new boundaries for the regulation of financial innovation. Global Policy, 7(2): 227-36.

Bernards, N. and Campbell-Verduyn, M. (2019) Understanding technological change in finance through infrastructures. Review of International Political Economy, 26(5): 773-89.

Best, J. and Widmaier, W. (2006) Micro-or macro-moralities? Economic discourses and policy possibilities. Review of International Political Economy, 13(4): 609-31. 
Bousfield, D. (2019) Crypto-coin hierarchies: Social contestation in blockchain networks. Global Networks, 19(3): 291-307.

Brunton, F. (2019) New book reveals crypto's radical origins. Interview with Finn Brunton by Quin DuPont for Breakermag [Online], 22 March. Available at: <https://breakermag.com/new-bookreveals-cryptos-radical-origins/>. Accessed 9 June 2019.

Campbell-Verduyn, M. (2019) What does technology do? In: Leese, M. and Hoidonk, M. (eds.) Technology and Agency in International Relations. New York: Routledge, 113-40.

Campbell-Verduyn, M. (2017a) Capturing the moment? Crisis, market accountability, and the limits of legitimation. New Political Science, 39(3): 350-68.

Campbell-Verduyn, M. (2017b) Professional Authority after the Global Financial Crisis: Defending Mammon in Anglo-America. London: Palgrave.

Clarke, C. and Tooker, L. (2018) Social finance meets financial innovation: Contemporary experiments in payments, money and debt. Theory, Culture \& Society, 35(3): 3-11.

Coeckelbergh, M. and Reijers, W. (2015) Cryptocurrencies as narrative technologies. ACM SIGCAS Computers and Society, 45(3): 172-78.

Cox, J. (2013) Bitcoin bonanza: Cyprus crisis boosts digital dollars. CNBC [Online], 27 March. Available at: <https://www.cnbc.com/id/100597242>. Accessed 9 June 2019.

Czarniawska, B. (2011) Performativity in place of responsibility? Journal of Organizational Change Management, 24(6): 823-29.

Czarniawska, B. (2012) New plots are badly needed in finance: Accounting for the financial crisis of 2007-2010. Accounting, Auditing \& Accountability Journal, 25(5): 756-75.

Dagnes, A. (2013) Introduction. In: Dagnes, A. and Sachleben, M. (eds.) Scandal! An Interdisciplinary Approach to the Consequences, Outcomes, and Significance of Political Scandals. New York: Bloomsbury.

De Filippi, P. and Loveluck, B. (2016) The invisible politics of Bitcoin: Governance crisis of a decentralised infrastructure. Internet Policy Review, 5(3).

De Goede, M. (2015) Speculative values and courtroom contestations. South Atlantic Quarterly, 114(2): 355-75.

De Goede, M. (2001) Virtue, Fortune, and Faith: A Genealogy of Finance. Minneapolis: University of Minnesota Press.

De Vries, A. (2018) Bitcoin's growing energy problem. Joule, 2(5): 801-05.

Detrixhe, J. (2018) A dozen companies that reaped rewards by putting 'bitcoin' or 'blockchain' in their name. Quartz [Online], 12 January. Available at: <https://qz.com/1175701/putting-bitcoin-orblockchain-in-a-company-name-is-sometimes-enough-for-a-pop-on-the-stock-market/>. Accessed 20 November 2019.

Dierksmeier, C. and Seele, P. (2018) Cryptocurrencies and business ethics. Journal of Business Ethics, 152(1): 1-14.

Dodd, N. (2018) The social life of Bitcoin. Theory, Culture \& Society, 35(3): 35-56.

DuPont, Q. (2019) Cryptocurrencies and Blockchains. London: Polity.

DuPont, Q. (2017) Experiments in algorithmic governance: A history and ethnography of 'The DAO', a failed decentralized autonomous organization. In: Campbell-Verduyn, M. (ed.) Bitcoin and Beyond: Cryptocurrencies, Blockchains and Global Governance. London: Routledge, 157-77.

DuPont, Q. and Maurer, B. (2015) Ledgers and law in the blockchain. Kings Review [Online]. 23 June. Available at: <http://kingsreview.co.uk/magazine/blog/2015/06/23/ledgers-and-law-in-theblockchain>. Accessed 9 June 2019.

Ellis, D. (2016) Economic freedom mis-sold. In: Wiegratz, J. and Whyte, D. (eds.) Neoliberalism and the Moral Economy of Fraud. New York: Routledge, 155-69. 
Fourcade, M., Steiner, P., Streeck, W. and Woll, C. (2013) Moral categories in the financial crisis. SocioEconomic Review, 11(3): 601-27.

Golumbia, D. (2016) The Politics of Bitcoin: Software as Right-Wing Extremism. Minneapolis: University of Minnesota Press.

Harrington, B. (2014) The companies we keep: From legitimacy to reputation in retail investment. Socio-Economic Review, 12(1): 186-95.

Helleiner, E. (2014) The Status Quo Crisis: Global Financial Governance after the 2008 Meltdown. Oxford: Oxford University Press.

Hendrikse, R., Bassens, D. and Van Meeteren, M. (2018) The Appleization of finance: Charting incumbent finance's embrace of FinTech. Finance and Society, 4(2): 159-80.

Hozić, A.A. and True, J. (2017) Brexit as a scandal: gender and global trumpism. Review of International Political Economy, 24(2): 270-87.

Hozić, A.A. and True, J. (2016) Making feminist sense of the global financial crisis. In: Hozić, A.A., and True, J. (eds.) Scandalous Economics: Gender and the Politics of Financial Crises. Oxford: Oxford University Press, 3-20.

Hütten, M. (2019) The soft spot of hard code: Blockchain technology, network governance and pitfalls of technological utopianism. Global Networks, 19 (3): 329-48.

Jentzsch, C. (2016) Decentralized autonomous organization to automate governance. Slock.it [Online]. Available at: <https://download.slock.it/public/DAO/WhitePaper.pdf>. Accessed 9 June 2019.

Jeong, S. (2018) Dogecoin. In: Maurer, B. and Swartz, L. (eds.) Paid: Tales of Dongles, Checks, and Other Money Stuff. Cambridge, MA: MIT Press, 53-70.

Johnson, J.M. (2017) Beyond a politics of recrimination: Scandal, ethics and the rehabilitation of violence. European Journal of International Relations, 23(3): 703-26.

Karlstrøm, H. (2014) Do libertarians dream of electric coins? The material embeddedness of Bitcoin. Distinktion: Scandinavian Journal of Social Theory, 15(1): 23-36.

Kristoufek L. (2015) What are the main drivers of the Bitcoin price? Evidence from wavelet coherence analysis. PloS One, 10(4). Available at:

<https://journals.plos.org/plosone/article?id=10.1371/journal.pone.0123923>. Accessed 19 November 2019.

Krugman, P. (2013a) Bitcoin is evil. New York Times [Online]. 28 December. Available at: <https://krugman.blogs.nytimes.com/2013/12/28/bitcoin-is-evil/>. Accessed 9 June 2019.

Krugman, P. (2013b) The antisocial network of bitcoins. New York Times [Online], 15 April. Available at: <https://www.nytimes.com/2013/04/15/opinion/krugman-the-antisocial-network.html>. Accessed 9 June 2019.

Lotti, L. (2016) Contemporary art, capitalization and the blockchain: On the autonomy and automation of art's value. Finance and Society, 2(2): 96-110.

Luckmann, T. (2002) Moral communication in modern societies. Human Studies, 25(1): 19-32.

MacKenzie, D. (2010) Unlocking the language of structured securities. Financial Times, 18 August.

Maddox, A., Singh, S., Horst, H. and Adamson, G. (2016) An ethnography of Bitcoin: Towards a future research agenda. Australian Journal of Telecommunications and the Digital Economy, 4(1): 65-78.

Montag, A. (2018) Nobel-winning economist: Authorities will bring down 'hammer' on bitcoin. CNBC [Online], 9 July. Available at: <https://www.cnbc.com/2018/07/09/nobel-prize-winningeconomist-joseph-stiglitz-criticizes-bitcoin.html>. Accessed 9 June 2019.

Moschella, M. and Tsingou, E. (2013) Great Expectations, Slow Transformations: Incremental Change in Post-Crisis Regulation. Colchester: ECPR Press.

Nakamoto, S. (2008) Bitcoin: A peer-to-peer electronic cash system. Bitcoin.org [Online]. Available at: <https://bitcoin.org/bitcoin.pdf>. Accessed: 19 November 2019. 
Organization for Economic Cooperation and Development (2019) Initial Coin Offerings (ICOs) for SME Financing. OECD [Online]. Available at: <www.oecd.org/finance/initial-coin-offerings-for-smefinancing.htm>. Accessed 9 June 2019.

O'Leary, R.R. (2018) How a left-for-dead, \$0.22 crypto asset became a lifeline for activists. Coindesk [Online]. Available at: <https://www.coindesk.com/how-a-left-for-dead-0-22-crypto-asset-becamea-lifeline-for-activists>. Accessed 9 June 2019

Omarova, S.T. (2019) New tech v. new deal: Fintech as a systemic phenomenon. Yale Journal on Regulation, 36(2): 735-93.

Paul, R. (2009) End the Fed. New York: Grand Central Publishing.

Popper, N. (2016) A hacking of more than $\$ 50$ million dashes hopes in the world of virtual currency. New York Times [Online], 18 June. Available at: <https://www.nytimes.com/2016/06/18/business/dealbook/hacker-may-have-removed-morethan-50-million-from-experimental-cybercurrency-project.html>. Accessed 9 June 2019.

Redman, J. (2016). Charity DAO gives the original DAO a second chance. Bitcoin.com [Online], 21 November. Available at: <https://news.bitcoin.com/charity-dao-second-chance/>. Accessed 19 November 2019.

Rethel, L. (2011) Whose legitimacy? Islamic finance and the global financial order. Review of International Political Economy, 18(1): 75-98.

Rotolo, D., Hicks, D. and Martin, B.R. (2015) What is an emerging technology? Research Policy, 44(10): 1827-843.

Roubini, N. (2018) Initial coin scams. Financial News [Online], 10 May. Available at: <https://www.fnlondon.com/articles/nouriel-roubini-calling-out-initial-coin-scams-20180510>. Accessed 9 June 2019.

Scholte, J.A. (2013) Civil society and financial markets: What is not happening and why. Journal of Civil Society, 9(2): 129-47.

Stafford, P. and Murphy H. (2016) Has blockchain hype finally peaked? Financial Times, 29 November.

Swartz, L. (2018) What was Bitcoin, what will it be? The techno-economic imaginaries of a new money technology. Cultural Studies, 32(4): 623-50.

Tekobbe, C. and McKnight, J.C. (2016) Indigenous cryptocurrency: Affective capitalism and rhetorics of sovereignty. First Monday, 21(10).

Tett, G. (2019) Peak financial scandal? History says not. Financial Times, 9 January.

Thiel, C. (2011) Das „bessere Geld“: Eine ethnographische Studie über Regionalwährungen. Wiesbaden: VS Verlag für Sozialwissenschaften.

Thompson, E.P. (1971) The moral economy of the English crowd in the eighteenth century. Past \& Present, (50): 76-136.

Thrift, N. and Leyshon, A. (1999) Moral geographies of money. In: Gilbert, E. and Helleiner, E. (eds.) Nation-States and Money: The Past, Present and Future of National Currencies. London: Routledge, 159-81.

Tual, S. (2016) No DAO funds at risk following the Ethereum smart contract 'recursive call' bug discovery. Slock.it [Online], 12 June. Available at: <https://blog.slock.it/no-dao-funds-at-riskfollowing-the-ethereum-smart-contract-recursive-call-bug-discovery-29f482d348b>. Accessed 19 November 2019.

Tooze, A. (2018) Crashed: How a Decade of Financial Crises Changed the World. New York: Penguin. Tucker, P. (2018) Unelected Power: The Quest for Legitimacy in Central Banking and the Regulatory State. Princeton, NJ: Princeton University Press.

Vessens, P. (2016) More ethereum attacks: Race-to-empty is the real deal. Vesseness.com [Online], 9 June. Available at: <http://vessenes.com/more-ethereum-attacks-race-to-empty-is-the-real-deal/>. Accessed 9 June 2019. 
Weber, B. (2018) Democratizing Money? Debating Legitimacy in Monetary Reform Proposals.

Cambridge: Cambridge University Press.

Whyte, D. and Wiegratz, J. (2016) Neoliberalism, moral economy and fraud. In: Whyte, D. and Wiegratz, J. (eds.) Neoliberalism and the Moral Economy of Fraud. New York: Routledge, 1-16.

Zastrow, B. (2018) Kriptmobile and Dash Venezuela use case. Dash.org [Online], 18 December. Available at: <https://blog.dash.org/kriptomobile-dash-venezuela-use-case-7bb582528258/>. Accessed 27 November 2019. 